\title{
Managing Obesity by a Specialist Nurse
}

\section{Esra Keser ${ }^{1}$ and Sevgin Samancioglu Baglama2*}

\author{
${ }^{1}$ Adana Askim Tufekci State Hospital, Adana, Turkey \\ ${ }^{2}$ Gaziantep University Health Science Faculty, Gaziantep, Turkey
}

${ }^{*}$ Corresponding author: Sevgin Samancioglu Baglama, Gaziantep University Health Science Faculty, Gaziantep, Turkey, Tel: 03423606060 ; Email: sevginsamancioglu@hotmail.com

Received date: August 13, 2018; Accepted date: August 21, 2018; Published date: August 27, 2018

Copyright: (02018 Keser E, et al. This is an open-access article distributed under the terms of the Creative Commons Attribution License, which permits unrestricted use, distribution, and reproduction in any medium, provided the original author and source are credited.

Citation: Keser E, Baglama SS (2018) Managing Obesity by a Specialist Nurse. Health Syst Policy Res Vol. 5 No.2: 72

\section{Abstract}

Background and Aim: This study aimed to investigate the efficacy of nurse-led obesity management program. In the literature, there is a lack of studies conducted within the scope of nursing consultancy given to adult obese individuals.

Materials and Methods: The research was planned as a randomized controlled experimental study and was conducted at an endocrine-metabolic clinic of a public hospital. The study was comprised of 64 obeses. The selfefficacy of obese individuals in terms of exercise and eating habits was assessed using the exercise self-efficacy scale, the Self-Efficacy to regulate eating habits scale and the obesity and weight-loss quality-of-life (OWLQOL).

Results: It was determined that the nursing consultancy program based on health promotion model had a positive impact on individuals' eating habits, exercise self-efficacy levels, quality of life, healthy life behaviors and anthropometric measurements.

Conclusion: This study emphasizes the significance of the presence of "obesity nurse consultant" and the promotion of nurse consultancy practice in obesity management.

Keywords: Endocrine system; Eating habits; Nursing care management; Obesity

\section{Introduction}

Obesity, one of the major causes of preventable deaths, was declared as a global epidemic by World Health Organization (WHO) due to causes such as modernization and economic growth. In 2004, it was reported that there was more than 600 million obese in adult population [1].

It was reported that $35.0 \%$ of individuals aged above 20 years in the USA were obese and that weight gain was mostly observed in women aged 60 years and above [2]. Other developed countries succeed the USA regarding the prevalence of obesity. The prevalence of overweight affects $30.0 \%-70.0 \%$ and obesity affects $10.0 \%-30.0 \%$ of adults [3]. In Turkey, the increase in the prevalence of Turkey in the last 12 years is $34.0 \%$ in women while it is $10.0 \%$ in men [4].

According to the data obtained worldwide, the role of nurses in the protection and promotion of health is gradually gaining greater importance. The Health Goals of the $21^{\text {st }}$ Century also emphasize the concept of health promotion [5]. Pender's Health Promotion Model (HPM) evaluates the history and self-perception of individuals, and offers them a holistic approach.

The major aspect of this theory is that individuals make healthy life behaviors a part of their lives and they are offered consultancy. Individual's capability of organizing a necessary activity for a change of behavior and belief in success is named as "belief in self-efficacy" [6]. If a positive behavior change is reinforced in an individual, self-efficacy also increases. In brief, successful execution of behavior affects the self-efficacy belief of an individual.

In addition to self-efficacy, Pender also emphasizes the significance of consultancy in exercise, nutrition, interpersonal relations and stress management [6]. Self-efficacy is of great importance in initiating and sustaining a behavior change in individuals [5].

Therefore, individuals who receive nursing consultancy will develop healthy life behaviors and they will lead longer and better-quality lives [6]. There are studies which show that metabolically and psychosocially positive results are obtained as lifestyle of obese individual changes [7].

In this study, it was planned to create positive changes in the lifestyle of obese individuals regarding exercise and eating habits as well as their metabolic and anthropometric functional capacity values the nurse-led consultancy increasing self-efficacy. Our hypothesis is that nurse counseling received by obese individuals will increase their self-efficiency and quality of life. 


\section{Methods}

\section{Study design}

The research was planned as a randomized controlled experimental study in order to analyze the impact of individual nurse consultancy based on Pender's "HPM" on patients' anthropometric measurements, functional capacity, level of self-efficacy regarding exercise and nutrition and quality of life.

\section{Setting and sample}

The research was conducted at an endocrine-metabolic clinic of a public hospital between April 2015 and December 2015. The sample of the research was selected by simple random sampling method. As a result of the power analysis, the minimum required sample size was calculated to be $\alpha=0.05$ and while the power of the test was (1- $\beta) .80$ it was calculated to be 26 for each group. The sample of the research consisted of 70 individuals (35 for control group and 35 for consultancy group) who were diagnosed with obesity and who applied to the outpatient clinic on the dates specified, met the sample selection criteria of the research and volunteered to participate in the study. Thus, the number of samples was higher than expected. Over the course of the research, as 3 patients from the intervention group did not want to go for a checkup it ended up with 32 patients while 1 patient from the control group underwent bariatric surgery and 2 patients did not want to go for a checkup so the group ended up with 32 patients with a total research sample of 64 patients (Figure 1). The research included individuals who were 18 years plus, diagnosed with obesity for at least six months, had BMI of 30 and above, had no communication problem, no medication for obesity treatment, had not surgery, patients who do not carry cardiovascular risk at the end of physician control, no thyroid disorder or respiratory diseases such as asthma and chronic obstructive pulmonary disease (COPD), no pregnancy and volunteered to participate in the research.

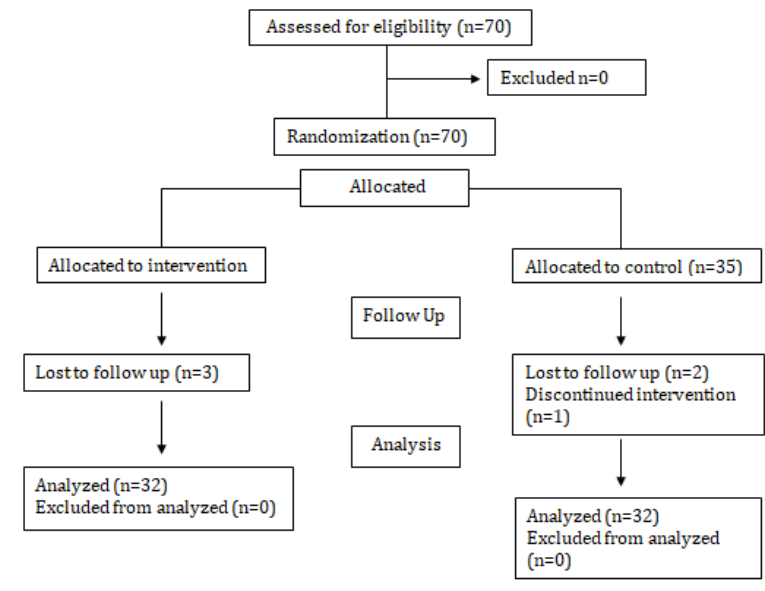

Figure 1: Consort flow diagram.

\section{Measurements}

Individual identification form: It is a form consisting of 29 questions that question the information on the sociodemographic and obesity-related characteristics of individuals, prepared by the researchers with the support of related literature $[8,9]$.

Functional capacity assessment form: For the functional capacity assessment of obese individuals; six minute walking test (6MWT), modified borg dyspnea scale and pulmonary function tests (PFT) were used. This form includes obese individual's oxygen supply condition during walk test, test timer, pre-test and post-blood pressure, heart rate, dyspnea degree, oxygen saturation, possible symptoms (dizziness, back pain, knee pain, leg pain), test release status and information on walking distance.

Six minute walking test (6MWT): It was developed by Balke in 1963 to assess functional capacity. 6MWT is a test which provides indirect information on the exercise capacity and functional capacity of individuals [10]. This test was conducted according to the instructions given in the American Thoracic Society Guide [11].

Modified borg scale: The original Borg Scale was developed by Borg in 1982 to assess the exertion made in physical exercise [12]. In 1986, the American college of sports medicine rearranged the scale with ratings between 0 and 10 [11].

Pulmonary function tests (PFT): PFT were conducted with spirometric (Flowhandy, ZAN 100) method [13]. The test to be conducted was initially explained and demonstrated to obese individuals.

Exercise self-efficacy scale: The scale shows the regular exercise capability of participants. The scale which was developed by Albert Bandura in 1997 consists of 18 items [14]. As the score received from the scale increases, the self-efficacy of the individual also increases and vice versa. For this study, the Cronbach's $\alpha$ value of the scale was found to be 0.98 .

The self-efficacy to regulate eating habits scale: The scale developed by Albert Bandura assesses the regular eating habits of participants and consists of 30 items [14]. The scale shows the individual scoring of participants regarding their performance of regular eating. There is a linear relationship between scale score and self-efficacy. The scale's Cronbach's $\alpha$ value for Turkish society was 0.98 [15]. For this study, the Cronbach's $\alpha$ value was also found to be 0.98 .

The obesity and weight-loss quality-of-life (OWLQOL): OWLQOL is a 17-item, 6 point Likert type scale developed by Patrick et al. in order to assess the impact of obesity on individuals' quality of life. It is a single-factor scale with no subdomains [16]. The scale's Cronbach's $\alpha$ value for Turkish society was found to be 0.90 [8]. For this study, the Cronbach's $\alpha$ value was also found to be 0.85 .

\section{Data collection}

Obese individuals were categorized into two groups as control and intervention. And questionnaires were applied 
after the first interview and in the $12^{\text {th }}$ week following the first meeting to assess the impact of the nurse counseling. In the first interview, the control and intervention groups were given question forms and surveys. This process lasted for 40-45 minutes for each obese individual. Interviews with obese individuals were conducted face-to-face and individually. In the research, data were collected by using individual identification form, functional capacity assessment form, exercise selfefficacy scale, the self-efficacy to regulate eating habits scale, owlqol and modified borg scale were used.

\section{Intervention}

After the first interview, the intervention group was given training and consultancy materials while the control group was allocated to routine monitoring.

Counseling for obese individuals included training (booklets including information on nutrition, physical activity and social relationships were provided to obese individuals in the first interview), telephone conversations twice a week and reminders to use at home. While the nutrition plan was followed up weekly, weaknesses of the obese individuals were improved, they were guided about the appropriate movements for physical activity, and motivation was increased with phone calls and the magnets that were attached to visible places such as fridges. According to the literature, it was considered that a 12-week follow-up was sufficient for behavioral change $[17,18]$.

\section{Theoretical Framework}

In this model, the aim is to make individuals develop health promoting behaviors. The training book provided to the intervention group within the scope of the nurse-led obesity consultancy program was prepared by the researchers based on related literature and Pender's HPM [6].

Of the health promoting behaviors specified in the model, the strongest characteristic and the most effective factor on behavior change is the perception of self-efficacy $[6,19]$.

The training basically encompasses the definition of obesity; the factors causing obesity; the significance of behavior change and increasing self-efficacy and the planning of individual-specific exercise and nutrition. The theoretical framework of this study is given in the Figure $\mathbf{2}$.

Table 1: Characteristics of the obese individuals $(n=64)$.

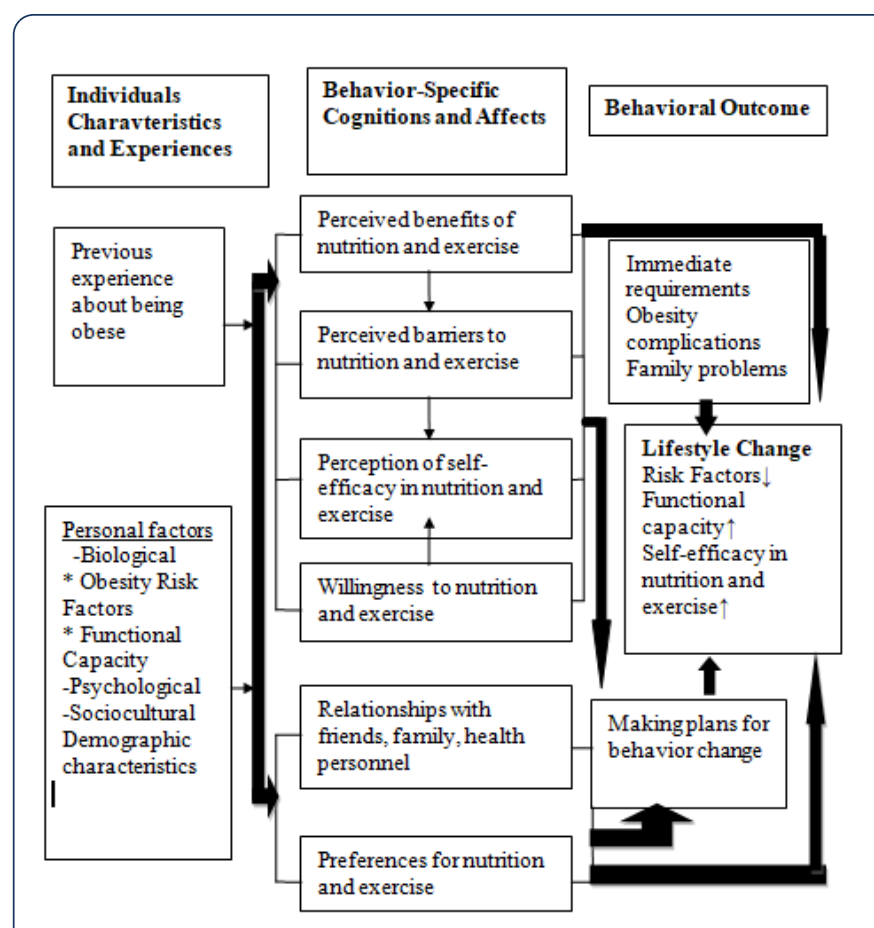

Figure 2: Application of health promotion model in obese individuals.

\section{Data Analysis}

The consistency of numerical data with normal distribution was tested with the Shaphiro-Wilk test. For the statistical evaluation of data obtained from the research, Statistical Package for Social Sciences (SPSS) 22.0 was used. Chi-Square and difference between two means significance test (Independent samples T test) were used. $\mathrm{P}<0.05$ was found to be significant.

\section{Results}

The mean age of the individuals in the consultancy group was $39.40 \pm 7.43$ years while that of the control group was $36.37 \pm 6.35$ years. Of the obese individuals in the consultancy and control group, $62.5 \%$ were female while $37.5 \%$ were male. Most of the obese individuals were married (85.9\%). It was found that $40.5 \%$ of the consultancy group and $46.8 \%$ of the control group had parental history of obesity (Table 1).

\begin{tabular}{|c|c|c|c|}
\hline Characteristics & Intervention Group n (\%) & Control Group n (\%) & Significance Test \\
\hline & $39.40 \pm 7.43$ & $36.37 \pm 6.35$ & $p=.085$ \\
\hline Mean Age $(y r) X \pm S D$ & - & - & $\mathrm{T}=.568$ \\
\hline \multicolumn{4}{|l|}{ Gender } \\
\hline Female & $20(62.5)$ & $20(62.5)$ & $p=1.000$ \\
\hline
\end{tabular}




\begin{tabular}{|c|c|c|c|}
\hline Male & $12(37.5)$ & $12(37.5)$ & $x^{2}=.001$ \\
\hline \multicolumn{4}{|l|}{ Educational Status } \\
\hline 5 years & $3(9.4)$ & $6(18.8)$ & $p=.281$ \\
\hline$\geq 6$ years & $29(90.6)$ & $26(81.2)$ & $x^{2}=1.164$ \\
\hline \multicolumn{4}{|l|}{ Marital status } \\
\hline Married & $28(87.5)$ & $27(84.4)$ & $p=.719$ \\
\hline Single & $4(12.5)$ & $5(15.6)$ & $x^{2}=.129$ \\
\hline \multicolumn{4}{|l|}{ Employment status } \\
\hline Employed & $28(87.5)$ & $30(93.8)$ & $p=.391$ \\
\hline Unemployed & $4(12.5)$ & $2(6.2)$ & $x^{2}=.736$ \\
\hline \multicolumn{4}{|l|}{ Obese parent } \\
\hline Mother & $6(18.73)$ & $8(24.96)$ & $p=.228$ \\
\hline Father & $4(12.49)$ & $1(3.12)$ & $x^{2}=2.958$ \\
\hline Mother and Father & $3(9.36)$ & $6(18.72)$ & - \\
\hline Total & $32(100.0)$ & $32(100.0)$ & - \\
\hline
\end{tabular}

The mean WHR (waist-to-hip ratio) of obese individuals who received consultancy from nurses fell from $0.87 \pm 0.08$ to 0.86 $\pm 0.08(p=0.035 ; T=2.15)$. Furthermore, a statistically non-

In this study, it was found that the BMI and WHR values of the participants in the control group who did not receive nurse counseling, increased (Table 2). significant fall was detected $(p>0.05)$ in body weight and BMI.

Table 2: Comparison of the anthropometric measurements of the obese individuals $(n=64)$.

\begin{tabular}{|c|c|c|c|c|}
\hline & \multicolumn{2}{|l|}{$\begin{array}{l}\text { Pre-monitoring } \\
\text { Mean } \pm \text { SD }\end{array}$} & \multicolumn{2}{|l|}{$\begin{array}{l}12^{\text {th }} \text { week } \\
\text { Mean } \pm \text { SD }\end{array}$} \\
\hline & $\begin{array}{l}\text { Intervention } \\
(n=32)\end{array}$ & $\begin{array}{l}\text { Control } \\
(n=32)\end{array}$ & $\begin{array}{l}\text { Intervention } \\
(n=32)\end{array}$ & $\begin{array}{l}\text { Control } \\
(n=32)\end{array}$ \\
\hline $\mathrm{BMI}\left(\mathrm{kg} / \mathrm{m}^{2}\right)$ & $33.56 \pm 3.23$ & $33.29 \pm 3.08$ & $31.26 \pm 3.36$ & $34.82 \pm 3.26$ \\
\hline $\mathrm{T}$ & 0.344 & - & -4.297 & - \\
\hline $\mathrm{P}$ & 0.732 & - & 0.001 & - \\
\hline Weight (kg) & $89.84 \pm 12.91$ & $88.40 \pm 11.16$ & $83.87 \pm 13.20$ & $92.46 \pm 11.87$ \\
\hline $\mathrm{T}$ & 0.476 & - & -2.738 & - \\
\hline $\mathrm{P}$ & 0.636 & - & 0.008 & - \\
\hline Waist (cm) & $101.37 \pm 10.62$ & $106.28 \pm 9.15$ & $95.56 \pm 11.37$ & $109.06 \pm 9.10$ \\
\hline $\mathrm{T}$ & -1.979 & - & -5.241 & - \\
\hline$P$ & 0.052 & - & 0.001 & - \\
\hline Hip (cm) & $115.50 \pm 7.79$ & $115.59 \pm 8.37$ & $110.00 \pm 7.66$ & $118.40 \pm 8.94$ \\
\hline $\mathrm{T}$ & -0.046 & - & -4.039 & - \\
\hline$P$ & 0.963 & - & 0.001 & - \\
\hline Waist/hip & $0.875 \pm .084$ & $0.915 \pm .064$ & $.865 \pm .088$ & $0.917 \pm .061$ \\
\hline $\mathrm{T}$ & -2.158 & - & -2.745 & - \\
\hline $\mathrm{P}$ & 0.035 & - & 0.008 & - \\
\hline
\end{tabular}


Individuals were given a 6MWT for the assessment of functional capacity and the physical findings of patients were recorded. It was seen that the FEV1/FVC ratio in the consultancy group was preserved $(p>0.05)$. It was found that the nurse consultancy model had a positive impact on the walking distance value of obese individuals and that this condition was statistically significant $(p<0.05 ; T=3.751)$. It was observed that the mean walking distance of obese individuals who received consultancy rose from $680.62 \pm 59.90 \mathrm{~cm}$ to $692.87 \pm 57.20 \mathrm{~cm}$. Furthermore, a significant decrease in the respiratory rate $(p<0.05)$ and a non-significant decrease in SBP (systolic blood pressure); DBP (diastolic blood pressure) and pulse/min value of these individuals was determined ( $p>0.05)$. It was found that the nurse consultancy model had a positive impact on the mean dyspnea scores of obese individuals and that this condition was statistically significant $(p<0.05$; $T=6.740)$. With the nurse consultancy model, the mean dyspnea score of obese individuals fell from $3.15 \pm 1.24$ to 2.62 \pm 0.70 , while other values except for blood pressure and pulse rate were worsened in the control group (Table 3).

Table 3: Comparison of the functional capacity levels of the obese individuals $(n=64)$.

\begin{tabular}{|c|c|c|c|c|}
\hline & \multicolumn{2}{|l|}{$\begin{array}{l}\text { Pre-monitoring } \\
\text { Mean } \pm \text { SD }\end{array}$} & \multicolumn{2}{|l|}{$\begin{array}{l}12^{\text {th }} \text { week } \\
\text { Mean } \pm S D\end{array}$} \\
\hline & $\begin{array}{l}\text { Intervention } \\
(n=32)\end{array}$ & $\begin{array}{l}\text { Control } \\
(n=32)\end{array}$ & $\begin{array}{l}\text { Intervention } \\
(n=32)\end{array}$ & $\begin{array}{l}\text { Control } \\
(n=32)\end{array}$ \\
\hline FVC & $101.90 \pm 11.87$ & $106.62 \pm 13.39$ & $103.28 \pm 12.27$ & $97.65 \pm 11.31$ \\
\hline $\mathrm{T}$ & -1.491 & - & 1.906 & - \\
\hline$P$ & 0.141 & - & 0.061 & - \\
\hline FEV1 & $102.68 \pm 12.41$ & $105.87 \pm 13.34$ & $103.90 \pm 11.86$ & $98.28 \pm 11.73$ \\
\hline $\mathrm{T}$ & -0.989 & - & 1.907 & - \\
\hline $\mathrm{P}$ & 0.326 & - & 0.061 & - \\
\hline FEV1/FVC & $105.43 \pm 3.70$ & $103.84 \pm 4.57$ & $105.96 \pm 4.41$ & $100.25 \pm 8.43$ \\
\hline $\mathrm{T}$ & 1.532 & - & 3.398 & - \\
\hline $\mathrm{P}$ & 0.131 & - & 0.001 & - \\
\hline Walking distance $(\mathrm{m})$ & $680.62 \pm 59.90$ & $629.37 \pm 48.85$ & $692.87 \pm 57.20$ & $623.56 \pm 48.51$ \\
\hline $\mathrm{T}$ & 3.751 & - & 5.227 & - \\
\hline $\mathrm{p}$ & 0.001 & - & 0.001 & - \\
\hline $\mathrm{SBP}(\mathrm{mm} / \mathrm{Hg})$ & $123.90 \pm 12.68$ & $125.93 \pm 9.01$ & $117.81 \pm 10.62$ & $124.84 \pm 9.62$ \\
\hline $\mathrm{T}$ & 0.738 & - & 2.774 & - \\
\hline $\mathrm{P}$ & 0.463 & - & 0.007 & - \\
\hline $\mathrm{DBP}(\mathrm{mm} / \mathrm{Hg})$ & $78.59 \pm 7.95$ & $81.71 \pm 6.30$ & $71.56 \pm 7.97$ & $78.12 \pm 4.70$ \\
\hline $\mathrm{T}$ & 1.742 & - & 4.008 & - \\
\hline $\mathrm{P}$ & 0.086 & - & 0.001 & - \\
\hline Pulse (min) & $83.09 \pm 10.72$ & $84.37 \pm 9.72$ & $78.71 \pm 8.15$ & $82.87 \pm 7.66$ \\
\hline $\mathrm{T}$ & 0.501 & - & 2.1 & - \\
\hline $\mathrm{p}$ & 0.618 & - & 0.04 & - \\
\hline Respiratory (min) & $21.56 \pm 1.77$ & $20.75 \pm 1.04$ & $20.62 \pm 1.26$ & $20.96 \pm 1.17$ \\
\hline $\mathrm{T}$ & 2.229 & - & 1.126 & - \\
\hline $\mathrm{p}$ & 0.029 & - & 0.265 & - \\
\hline BORG & $3.15 \pm 1.24$ & $1.46 \pm 0.67$ & $2.15 \pm 1.05$ & $2.62 \pm 0.70$ \\
\hline $\mathrm{T}$ & 6.74 & - & -2.094 & - \\
\hline $\mathrm{p}$ & 0.001 & - & 0.04 & - \\
\hline
\end{tabular}


The primary endpoint of this study was defined as an increase in self-efficacy, while the secondary endpoint was defined as an increase in quality of life. It was determined that the nurse consultancy model applied to obese individuals increased the level of nutrition and exercise self-efficacy, and improved quality of life $(p<0.05)$. It is seen that the nurse consultancy model has a positive impact on the regulation of the eating habits of obese individuals and exercise self-efficacy mean scores with a statistical significance $(p=0.054, T=1.996$, $\mathrm{p}<0.05 ; \mathrm{T}=4.539$ respectively). In the nurse consultancy group, it was seen that total OWLQOL mean score was positively affected however it was not statistically significant ( $p>0.052$; $\mathrm{T}=0.192)$. With a three-month nurse consultancy model, the total OWLQOL mean score rose from $33.37 \pm 11.65$ to $55.15 \pm$ 12.97. In the control group, both nutrition and exercise selfefficacy scores and total quality of life scores decreased (Table 4).

Table 4: Comparison of nutrition self-efficacy, exercise self-efficacy and quality of life scores of obese individuals.

\begin{tabular}{|c|c|c|c|c|}
\hline & \multicolumn{2}{|c|}{$\begin{array}{l}\text { Pre-monitoring } \\
\text { Mean } \pm \text { SD }\end{array}$} & \multicolumn{2}{|l|}{$\begin{array}{l}12^{\text {th }} \text { week } \\
\text { Mean } \pm \text { SD }\end{array}$} \\
\hline & $\begin{array}{l}\text { Intervention } \\
(n=32)\end{array}$ & $\begin{array}{l}\text { Control } \\
(n=32)\end{array}$ & $\begin{array}{l}\text { Intervention } \\
(n=32)\end{array}$ & $\begin{array}{l}\text { Control } \\
(n=32)\end{array}$ \\
\hline Nutrition Self-efficacy & $41.54 \pm 20.80$ & $52.69 \pm 23.77$ & $60.95 \pm 17.38$ & $35.17 \pm 15.16$ \\
\hline $\mathrm{T}$ & 1.996 & - & 6.323 & - \\
\hline$P$ & 0.05 & - & 0.001 & - \\
\hline Exercise Self-efficacy & $30.18 \pm 27.21$ & $57.48 \pm 20.40$ & $57.06 \pm 22.04$ & $31.88 \pm 17.77$ \\
\hline $\mathrm{T}$ & 4.539 & - & 5.031 & - \\
\hline$P$ & 0.001 & - & 0.001 & - \\
\hline Quality of Life & $33.37 \pm 11.65$ & $32.78 \pm 13.02$ & $55.15 \pm 1.97$ & $20.15 \pm 10.10$ \\
\hline $\mathrm{T}$ & 0.192 & - & 12.04 & - \\
\hline$P$ & 0.848 & - & 0.001 & - \\
\hline
\end{tabular}

\section{Discussion}

Taking more energy than necessary to the body, adverse changes in lifestyle and fast food have caused a rapid increase in the prevalence of obesity in recent years [20].

Similar to this study, it was determined that the threemonth physical activity program applied to overweight and obese women by Bambal et al. was effective on the anthropometric indicators of obesity such as BMI, waist circumference, hip circumference and weight [21]. It is known that obese individuals, who are taken to a program to increase exercise, improve eating habits and lose weight experience weight loss [9]. In another study, it was determined that obese individuals with a high level of physical activity knowledge and weight loss self-efficacy experienced a decrease in their BMI level [22]. It was stated that the exercises done reduced weight and had a positive impact on body composition and flexibility [23]. Deterioration observed in pulmonary function without lung disease increases with the severity of obesity [24]. Weight loss together with improvement in lung function in obese individuals is expressed by the reduction of mass effect in obesity by weight loss [25]. In this study, the FEV1/FVC ratio has been preserved in the intervention group ( $p>0.05)$. In the literature, it has been shown that there is a negative correlation between pulmonary function test values and BMI and that exercise has a positive impact $[24,26]$. In this study, it was observed that there was a decrease in the $\mathrm{BMI}$ values and an increase in the walking distance of obese individuals managed by nurses after the $12^{\text {th }}$ week. This shows a similarity with the findings of studies conducted with obese individuals in the literature. As the BMI value decreases, walking distance increases [27]. While non-significant falls were observed in the pulse number, systolic and diastolic blood pressure of obese individuals who received nurse consultancy $(p>0.05)$, there was a significant fall in the systolic blood pressure of obese individuals in the control group $(p<0.01)$. The studies conducted demonstrate the positive impact of exercise on cardiovascular fitness and cardiovascular disease risk factors [18]. In this study, it was not possible to assess what particular cause affected the control group, while regular physical exercise and compliance with diet were effective on the counseling group regarding the improvement of blood pressure.

In previous studies, it was determined that level of selfefficacy had an impact on eating behaviors and that it was a significant indicator of weight loss [20]. In the other studies conducted, it was stated that lifestyle changes related with weight management including physical activity and nutrition had a positive impact on self-efficacy level, quality of life, and weight and waist circumference measurement [28]. In the study of Dogan and Ayaz, a positive correlation was found between self-efficacy level and perceived benefits of exercise [29]. In the study of Annesi, it was detected that there was a two-way correlation between self-efficacy level and physical activity in obese women who regained the weight they lost 
and that the use of self-regulatory skills increased with high self-efficacy level [9]. Furthermore, it is reported that obesity decreased quality of life at a significant level. In the study of Degirmenci et al. it was detected that individuals with obesity experienced significant problems in the physical subdomain of life quality compared to healthy control group [30]. When conditions such as a decrease in physical capacity, pain, deterioration in interpersonal relationships, decreased selfesteem, loss of confidence, depression, social stigmatization, employment difficulties and rejection in school and business circles are considered, it could be seen how low obese individuals' quality of life is in terms of health [8].

There is a limitation to this study. According to the sample size structure of the study, the findings cannot be generalized. It is recommended that future studies be planned for a longer term with a larger sample.

\section{Conclusion}

The results of this study demonstrate the significance of nurse consultancy applied to obese individuals. We anticipate that the data obtained in this three-month study will generate better results in a longer term and that the cost related with obesity will decline. The reason for this is that, without a consultant, these individuals continue following incorrect or harmful practices and wrong diet programs. These conditions create an inextricable situation for obese individuals. Obese individuals develop healthy lifestyle behaviors more rapidly when monitored and trained by a nurse. Furthermore, these individuals feel stronger as they receive support to the life they want to change.

\section{Acknowledgments}

The authors are grateful to the obeses who participated in this study.

\section{Ethical Consideration}

The study was approved by the University Ethics Committee for Non-Interventional Clinical Investigations (Nr: 2014/343). Furthermore, oral consent/not written consent was received from obese individuals who volunteered to participate in the study.

\section{Financial Support and Sponsorship}

This is a self-funding study.

\section{Conflicts of Interest}

The authors declared no conflicts of interest.

\section{References}

1. World Health Organisation (2015) Obesity and overweight.
2. Ogden CL, Carroll MD, Kit BK, Flegal KM (2014) Prevalence of childhood and adult obesity in the United States, 2011-2012. JAMA 311: 806-814.

3. World Health Organisation (2016) Data and statistics: The challenge of obesity-quick statistics.

4. Satman I, Omer B, Tutuncu Y, Kalaca S, Gedik S, et al. (2013) Twelve-year trends in the prevalence and risk factors of diabetes and prediabetes in Turkish adults. Eur J Epidemiol 28: 169-180.

5. Glanz K, Rimer BK, Viswanath K (2015) Health behavior and health education: theory. Research and practice (590). San Francisco: Jossey-Bass.

6. Pender NJ (2011) Health promotion model manual.

7. Foster GD, Wadden TA, LaGrotte CA, Veur SSV, Hesson LA, et al. (2013) A randomized comparison of a commercially available portion-controlled weight-loss intervention with a diabetes selfmanagement education program. Nutrition \& Diabetes 18: e63.

8. Gunduzoglu NC, Fadıloglu C, Yılmaz C (2014) The examination of validity and reliability for obese individuals specific quality of life scale. Anadolu Psikiyatri Dergisi 15: 63-68.

9. Annesi JJ (2016) Psychosocial predictors of decay in healthy eating and physical activity improvements in obese women regaining lost weight: Translation of behavioral theory into treatment suggestions. Transl Behav Med 6: 169-78.

10. Balke B (1963) A simplefield test for the assessment of physical fitness. REP 63-6. [Report]. Civil Aeromedical Research Institute (U.S) 1-8.

11. ATS committee on profiency standards for clinical pulmonary function laboratories (2002) ATS statement: Guidelines for the six-minute walk test. Am J Respir Crit Care Med 166: 111-117.

12. Borg G (1982) Ratings of perceived exertion and heart rates during short-term cycle exercise and their use in a new cycling strength test. Int J Sports Med 3: 153-158.

13. Miller MR, Hankinson J, Brusasco V, Burgos F, Casaburi R, et al. (2005) ATS/ERS task force: Standardisation of spirometry. Eur Respir J 26: 319-338.

14. Bandura A (1997) Self-efficacy: The exercise of control. New York: W. H. Freeman.

15. Sevinc S, Argon G (2014) Turkish reliability and validity of selfefficacy to regulate eating habits scale in the cardiac patients. J Ege University Nursing Faculty 30: 19-33.

16. Patrick DL, Bushnell DM, Rothman M (2004) Performance of two self-report measures for evaluating obesity and weight loss. Obesity Res 12: 48-57.

17. Tsai A, Wadden T (2009) Treatment of obesity in primary care practice in the united states: a systematic review. J Gen Int Med 24: 1073-1079.

18. Ritten A, Waldrop J, Joanne $K$ (2016) Fit living in progressfighting lifelong obesity pattern (FLIP- FLOP): A nurse practitionary delivered intervention. App Nurs Res 30: 119-124.

19. Bandura A (2004) Health promotion by social cognitive means. Health Educ Behav 31: 143-164.

20. Wilson LB, Hollins T, Clopton JR (2014) Construction and validation of the healthy eating and weight self-efficacy (HEWSE) scale. Eating Behav 15: 490-492.

21. Bambal OO, Dundar PE, Er G, Bayturan O (2015) Effectiveness of a physical activity program among overweight and obese women. Turkish J Public Health 13: 7. 
22. Faghri P, Buden J (2015) Health behavior knowledge and selfefficacy as predictors of body weight. J Nutr Disorders Ther 5(3): 1000169.

23. Cakmakci O (2011) The effect of 8 week pilates exercise on body composition in obese women. Collegium Antropologicum 35: 1045-1050.

24. Sutbeyaz ST, Ibrahimoglu F, Sezer N (2006) The effects of body fat distribution on pulmonary function and respiratory muscle strength in obese individuals. Turkish J Phys Med Rehabil 52 15-18.

25. Okur HK, Karip AB, Aras O, Tasdelen I, Altun H, et al. (2014) Respiratory function changes in female patients who have undergone obesity surgery. Marmara Med J 27: 32-35.

26. Sarsan A, Alkan H, Baser S, Yıldız N, Ozgen M, et al. (2013) The effect of aerobic exercise program on pulmonary function and cardiorespiratory capacity in obese women. Turkish J Phys Med Rehabil 59: 140-144.
27. Retory $\mathrm{Y}$, de Picciotto $\mathrm{C}$, Niedzialkowski $\mathrm{P}$, Petitjean $\mathrm{M}$, Bonay $\mathrm{M}$ (2016) Body mass index-dependent ventilatory parameters from respiratory inductive plethysmography during 6minute walk test. Respiratory Care 61: 521-528.

28. Cannon S, Lawry K, Brudell M, Rees R, Wenke R, et al. (2016) Appetite for change: A multidisciplinary team approach to behavioral modification for weight management in a community health group setting. Eat Weight Disord 21: 661-668.

29. Dogan R, Ayaz S (2015) Exercise behaviours, self-sufficiency levels of nurses and related factors. J Anatolia Nurs Health Sci 18: 4 .

30. Degirmenci T, Kalkan-Oguzhanoglu N, Sozeri-Varma G, Ozdel O, Fenkci S (2015) Psychological symptoms in obesity and related factors. Arch of Neuropsychiatry 52: 42-46. 